\title{
ОПЫТ ПРИМЕНЕНИЯ ПРЕПАРАТА ЦИКЛОДИНОН ДЛЯ ПРОФИЛАКТИКИ РЕЦИДИВА КИСТ МОЛОЧНЫХ ЖЕЛЕЗ ПОСЛЕ ПУНКЦИОННОЙ АСПИРАЦИИ
}

$\mathrm{H}$ аиболее распространенными нарушениями женской половой сореры в Украине являются дисгормональные расстройства, что связано с ухудшением экологической обстановки, хроническим стрессом, особенностями питания, изменениями репродуктивного и сексуального поведения населения. Эти и многие другие фракторы приводят к дисгормональным заболеваниям молочной железы, которые чаще всего объединяются термином «мастопатия».

Лечение мастопатии должно устранять причины, провоцирующие возникновение заболевания, гармонизировать работу нейроэндокринной системы, ликвидировать дисбаланс гормонов в тканях молочных желез.

Единого подхода к консервативному лечению мастопатии не существует, что вполне закономерно по причине полиэтиологичности и сложности патогенеза дисгормональных расстройств. Целью комплексного лечения мастопатии является улучшение качества жизни за счет устранения субъективных проявлений болезни, нормализации гормонального дисбаланса, а также профилактика пролифреративных форм фриброзно-кистозной мастопатии, что в конечном итоге призвано уменьшить заболеваемость раком молочных желез.

По данным литературных источников, наиболее частый вид гормонального дисбаланса - гиперпролактинемия. Распространенным вариантом мастопатии при гиперпролактинемии является орормирование кист. При консервативном лечении кист размером более $1 \mathrm{~cm}^{3}$ часто применяется пункционная эвакуация под контролем ультразвукового исследования (УЗИ-контроль). Согласно нашим данным, частота рецидива кист после пункции составляет примерно 20\%, что обусловлено сохраняющимися гормональными нарушениями, такими как гиперпролактинемия, явления относительного эстрогенного доминирования. Однако даже такое радикальное лечение, как пункция кистозных образований, нуждается в закрепляющей и противорецидивной терапии, направленной на устранение гормональных нарушений. Это связано с тем, что пункция не влияет на циклическую мастодинию и сопутствующие нарушения менструального цикла.

В настоящее время имеется большой арсенал синтетических лекарственных средств, ингибирующих синтез пролактина. Однако их применение ограничено из-за значительных побочных эффректов, а также трудностей лабораторного определения степени нарушения гормонального гомеостаза (неравномерность во времени секреции пролактина; возможность преобладания фрракции малого пролактина, проявляющего наивысшую биологическую активность, при нормальных показателях общего пролактина; изменение количества и чувствительности рецепторов к пролактину и др.).

В нашей практике для лечения подобных состояний хорошо зарекомендовал себя немецкий растительный препарат экстракта плодов прутняка обыкновенного (Vitex agnys castus) - Циклодинон, который может применяться без учета особенностей нарушений пролактинового гомеостаза. Многократными фрармакологическими и клиническими исследованиями было доказано, что содержащиеся в Циклодиноне биофрлавоноиды (бициклические дитерпены) прутняка (авраамова дерева) обладают уникальной природной способностью воздействовать на допаминовые $\mathrm{D}_{2}$-рецепторы лактофроров гипофриза и тем самым ингибировать избыточную продукцию пролактина. Патофизиологически это блокирует латентную гиперпролактинемию, транзиторную гиперпролактинемию, что также способствует восстановлению циклической продукции гонадотропных гормонов гипофиза, выравниванию эстроген-прогестеронового равновесия. Клинически это проявляется сужением расширенных протоков молочных желез, снижением активности пролиферативных процессов и регрессом соединительнотканного компонента, а также восстановлением фрункции яичников.

Лечение Циклодиноном сопровождается уменьшением отечности молочных желез, их нагрубания в предменструальный период. Соответственно купируется основной симптом

\begin{tabular}{|c|c|c|c|c|c|}
\hline \multirow[t]{2}{*}{ Показатели } & \multicolumn{2}{|c|}{$\begin{array}{c}\text { Основная } \\
\text { группа } \\
(n=122)\end{array}$} & \multicolumn{2}{|c|}{$\begin{array}{c}\text { Контрольная } \\
\text { группа } \\
(\mathrm{n}=31)\end{array}$} & \multirow{2}{*}{$\begin{array}{c}\text { Разница } \\
\text { результов между } \\
\text { группами, \% }\end{array}$} \\
\hline & $\mathbf{n}$ & $\%$ & n & $\%$ & \\
\hline Отсутствие кисты & 91 & 74,6 & 20 & 64,5 & $+15,7$ \\
\hline Остаточная полость кисты до 5 мм & 23 & 18,8 & 7 & 22,6 & $-16,8$ \\
\hline Рецидив кисты & 8 & 6,6 & 4 & 12,9 & $-48,8$ \\
\hline
\end{tabular}
больница № 19, городской онкологический центр,

г. Днепропетровск

А.Н. ГАЦУК

Городская клиническая больница № 19, городской онкологический центр,

г. Днепропетровск

А.В. ПАРФЕНТЬЕВ

Городская клиническая больница №19, городской онкологический центр

г. Днепропетровск

Н.Г. ШАПИРКО

Городская клиническая

больница № 19, городской онкологический центр,

г. Днепропетровск

В.Г. ШИРИНКИН

Городская клиническая больница № 19, городской онкологический центр, г. Днепропетровск
С.К. АЗАТЯН 


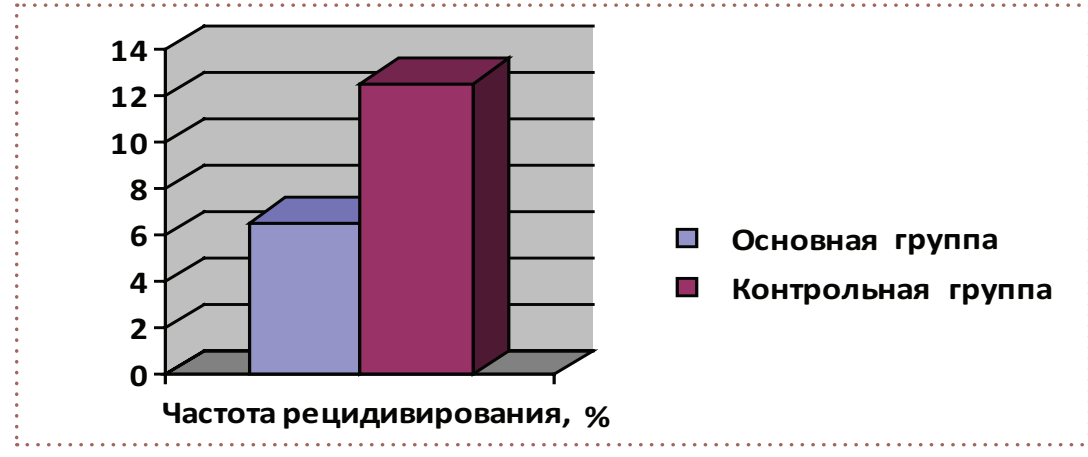

РИСУНОК.

ЧАСТОТА РЕЦИДИВА КИСТ

ЧЕРЕЗ 2 НЕД ПОСЛЕ ЛЕЧЕНИЯ

мастопатии - масталгия. Кроме того, препарат нормализует менструальный цикл, повышает адаптивные свойства организма, снижает интенсивность головной боли.

Противопоказания к приему препарата неизвестны, крайне редко проявляется индивидуальная непереносимость. Случаи передозировки Циклодинона не зарегистрированы, отрицательного влияния на способность к вождению данный препарат не оказывает.

ТАБЛИЦА 2

\begin{tabular}{|l|c|c|c|c|}
\hline \multicolumn{1}{|c|}{ Показатели } & \multicolumn{2}{|c|}{ Основная группа (n= 8) } & \multicolumn{2}{|c|}{ Контрольная группа (n=4) } \\
\hline Отсутствие кисты & $\mathbf{n}$ & $\mathbf{\%}$ & $\mathbf{n}$ & $\%$ \\
\hline $\begin{array}{l}\text { Остаточная полость } \\
\text { кисты до 5 мм }\end{array}$ & 4 & 50 & 0 & 0 \\
\hline Рецидив кисты & 3 & 37,5 & 2 & 50 \\
\hline
\end{tabular}

ТАБЛИЦА 2.

РЕЗУЛЬТАТЫ УЗИ МОЛОЧНЫХ ЖЕЛЕЗ ЧЕРЕЗ 4 НЕД ПОСЛЕ ЛЕЧЕНИЯ

\section{ЦЕЛЬ ИССЛЕДОВАНИЯ}

В нашей клинике мы провели оценку непосредственных результатов лечения препаратом Циклодинон после пункционной аспирации неосложненных кист (без признаков пролиферации, атипии и воспаления при патоцитологическом исследовании), которая основывалась на УЗИ-контроле наличия/ отсутствия остаточной полости кисты после пункции через 2 нед и через 3 мес. Остаточную полость толщиной более 5 мм расценивали как рецидив и проводили повторную эвакуацию содержимого.

ТАБЛИЦА 3

\begin{tabular}{|c|c|c|c|c|c|}
\hline \multirow{2}{*}{ Показатели } & \multicolumn{2}{|c|}{$\begin{array}{l}\text { Основная группа } \\
(\mathrm{n}=122)\end{array}$} & \multicolumn{2}{|c|}{$\begin{array}{c}\text { Контрольная группа } \\
(\mathrm{n}=31)\end{array}$} & \multirow{2}{*}{$\begin{array}{c}\text { Динамика } \\
\text { показателя } \\
\text { под влиянием } \\
\text { лечения, \% }\end{array}$} \\
\hline & $\mathrm{n}$ & $\%$ & $n$ & $\%$ & \\
\hline Отсутствие кисты & 87 & 71,3 & 16 & 51,6 & $+38,2$ \\
\hline $\begin{array}{l}\text { Остаточная полость кисты } \\
\text { до } 5 \text { мм }\end{array}$ & 26 & 21,3 & 9 & 29,0 & $-26,6$ \\
\hline Рецидив кисты & 9 & 7,4 & 6 & 19,4 & $-61,9$ \\
\hline
\end{tabular}

ТАБЛИЦА 3.

РЕЗУЛЬТАТЫ УЗИ МОЛОЧНЫХ ЖЕЛЕЗ ЧЕРЕЗ 3 МЕС ПОСЛЕ ЛЕЧЕНИЯ (по предпочтению пациентки) 2 раза в день первые 2 нед после аспирации кисты, а далее после УЗИ-контроля - 1 раз в день утром в течение 3 мес.

Контрольная группа, состоящая из 31 женщины, была сформирована ретроспективно на основании анализа амбулаторных карт пациенток, которые не получали антипролактиновых препаратов.

\section{РЕЗУЛЬТАТЫ ИССЛЕДОВАНИЯ И ИХ ОБСУЖДЕНИЕ}

При монотерапии Циклодиноном в основной группе положительные результаты зафиксированы у $77 \%$ женщин. Пациентки отмечали нормализацию менструального цикла, уменьшение выраженности проявлений предменструального синдрома, масталгии. Препарат пациентки переносили хорошо, аллергических реакций и побочных эффректов лечения не было зафриксировано.

В таблице 1 представлены данные УЗИконтроля через 2 нед после лечения.

Таким образом, применение циклодинона достоверно снижало частоту выявления остаточных полостей кист после аспирации на $16,8 \%$, а также частоту рецидивов на $48,8 \%$ через 2 нед после пункции (рис.).

При рецидиве кист были выполнены повторные пункционные аспирации, при УЗИконтроле еще через 2 нед (т.е. через 4 нед после исходного лечения), эффективность которых была выше у пациенток в группе приема Циклодинона, чем в группе контроля (табл. 2).

Также на фоне приема препарата Циклодинон достоверно уменьшилась необходимость в повторных аспирациях.

Данные УЗИ-контроля через 3 мес после проведенной терапии представлены в таблице 3.

Таким образом, применение Циклодинона по предложенной схеме достоверно снижало частоту выявления остаточных полостей кист после аспирации на $26,6 \%$, а частоту рецидивов - на 61,9\%. Эфрфективность лечения при этом повысилась на 38,2\%.

\section{Выводы}

Фитотерапевтический монокомпонентный негормональный препарат Циклодинон - эффективное средство для лечения различных проявлений дисгормональной мастопатии.

П Применение Циклодинона по предложенной схеме позволяет уменьшить количество рецидивов кист и соответственно - количество пункционных аспираций.

5 Циклодинон хорошо переносится, лечение не сопровождается побочными эффектами, что позволяет рекомендовать его как препарат выбора у пациенток с диффузной мастопатией с преобладанием кистозного компонента. 